\title{
Del documento al objeto digital
}

\author{
Celia Mire les Cárdenas \\ Escuela de Bibliotecología e Información \\ de la UniversidadAu tóno madeSanLuis Potosí
}

Elaspectomásexcitante deladocumen

tación digitaleslare definición deldocu

mentomismo

Bill Gates

\begin{abstract}
RESUMEN
Sepresentanlas principales caracterís ticas delos documentos tradicionales y los ahora llamados objetos digitales, así como las implicaciones en cuan to a su uso y es tu dio. Y tam bién al gu nas con si de ra cio nes so brela nece si dad de teo rizar so bre el do cu men to en es tos am bien tes di gi ta les a la bús que da de un concep to ade cua do quele permita a la dis ciplinabibliotecológica trabajar sobre este nuevo documento-objeto informativo que tiene implicaciones tan fundamentales para la profesión bibliotecóloga. Palabrasclave: Documen to, Documen to di gital, Obje to digital.
\end{abstract}

\section{FROM DOCUMENT TO DIGITAL OBJECT Celia Mireles-CáRdenas}

\begin{abstract}
Main charac teris tics of tra ditionaldocu ments and the so called digitalobjects are de fined, as well as the im pli ca tions in volved in the use and study of the lat ter. Also con sid ered is the need for a the ory of the docu ment in this digi tal en vi ron ment. The search is for an ade quate con cept which al lows the Library Science discipline to work on this new information document-object whoseim plica tions are so fun da men tal for the Library Science profession.

Key Words: Document; Digital Document; Digital Object
\end{abstract}

\section{INTRODUCCIÓN}

- 1 lpresentetrabajotiene comoobjetivoanalizaralgu nas de finicio nesqueexis ten sobre eldo cumento, eldo cumen to digitalyelobje to digital,y también describir las principales características de éstas dentro del actual contexto social y cultural marcado por la aplicación de modernas tecnologías a los procesos documentales que han transformado no sólo las concepciones tradicionales sobre lo textual, sino también su uso e impacto en la sociedad. 
Clarificarlosconceptosutilizados enlas disciplinasesimportante porque,aligual que las ciencias, con el tiempo evolucionan y se transforman, por lo que su revisión debe ser cons tan te pues son ellos mis mos los que mar can la pau ta para que un tér minoseaestudiadooconsiderado.

Un resultado no buscado, pero afortunado, fueron las referencias encontradas que so bre el libro y el do cu men to hacePaulOtleten Eltratado de documentación. Ellibro sobreellibro, don de una y otra vez se ade lan ta a su tiem po y pa re ce es tar des cribien do fe nó menos ac tua les. Así, sin ser el pro pó si to ini cial, ésta obra se con vir tió en fuen te de re fe rencia obliga da para re mi tirnos al pasa do, pre sen te y quizá tambiénal fu tu ro delmundodocumental.

Esteestudiofueparte delostrabajos realizadosdentrodelcurso "Normalización dela In for ma ción" im parti do por el doc tor Ro ber to Gar du ño Vera, a quien le agradezcosuapoyoparalarealizacióndelmismo.

\section{CONTEXTO SOCIAL Y CULTURAL DEL DOCUMENTO}

Laconvergenciadelastec nologíasdecomunicación,informáticayaudiovisuales llamadas comúnmente Tecnologías de Información y Comunicación (TICs), y su aplicaciónato daslas actividades productivas delhombre, transforma rondramáticamentelasconcepcionesterritoriales, espaciales,económicas,políticasyculturales de lasociedadduranteelúltimosiglo.

La cultura documental es generadora y consecuencia de estos cambios al presen tarnuevas for mas de lec tu ra y es cri tu ra: tex tua les, vi sua les y au di tivas, que requie ren a su vez de for mas dis tin tas para ser in ter pre ta das y apro piar se de sus contenidosinformativos.

PaulOtlet, apuntabaen rela ción conel surgimien to delos nuevos formatos documentalesdesuépoca:

Aparece un nuevo lenguaje gráfico hecho con el empleo simultáneo de diversos medios de expresión. Antes bastaba con apren der a leer los caracteres alfabéticos. Ahora hay que aprender a leer, a comprender los otros mo dos de ex pre sio nes grá ficas, y hay nue vos le tra dos y una cla se de nuevo analfabetismo. ${ }^{1}$

A pesar de los cambios, tan radicales en su presentación física, las principales trans formaciones deldocumen to se observan en cuan to a su contenido, porque "El tex to ya no es una en ti dad ce rraday pro te gi da, sino que estávolvien do aserun obje to abiertoypenetrable, librementecopiable einterpolablesinlímites"2 y den tro del cual laimagenessuprincipalcomponente.

1 Paul Otlet. pág. 75.

2 Raffaele Simone. Laterce rafase:formas de sa berque esta mosperdien do, p.137. 
Alsereldocu men to digital un producto del con tex to ac tual, in clu yelas carac te rísticas delaso cie dad quelogene ra. Algu nas de es tas ca rac te rís ticas pue den re su mirse enel análi sis que rea liza RaffaeleSimo ne ${ }^{3}$ so brelas nuevas for mas de co mu nica ción de las generaciones actuales y a las que nombra como "cultura no proposicional" (emergente), encontraparteconlaculturaproposi cional, propiadelascultu rasoccidentalesy delaculturacien tífica.Lasprincipales diferen cias deestascul turas se re sumenenelsiguientecuadrocomparativo:

Principalescaracterísticas de la cultura proposicional y no proposicional

\begin{tabular}{|c|c|}
\hline CulturaProposicional & Culturanoproposicional \\
\hline $\begin{array}{l}\text { 1. Analítica. } \\
\text { Ana li za cada fac tor, le da nom bre y es ta ble- } \\
\text { cerelaciones }\end{array}$ & $\begin{array}{l}\text { 1.Genérica: } \\
\text { Descomponeel con tenidoen ele men tos } \\
\text { que que dan in di fe ren cia dos y sin ana li- } \\
\text { zar, sólo los evo ca glo bal men te }\end{array}$ \\
\hline $\begin{array}{l}\text { 2. Es tructurada: } \\
\text { Le da a cada ele men to una je rar quía de ter- } \\
\text { minada }\end{array}$ & $\begin{array}{l}\text { 2.Re cha za la es truc tu ra y la je rar quía de } \\
\text { los componen tes, dejaal in ter lo cu torla } \\
\text { tarea de crear su propia es tructura. }\end{array}$ \\
\hline $\begin{array}{l}\text { 3. Co lo ca los da tos en el tiem po y el es pa- } \\
\text { cio. } \\
\text { Es ta ble ce una red de re fe ren cias y co ne xio- } \\
\text { nesrecíprocas }\end{array}$ & $\begin{array}{l}\text { 3. No le da nom bre a las co sas, sino que } \\
\text { las alu de usando "pala bras ge nerales". } \\
\text { Los ob je tos singu la res no tie nen nom- } \\
\text { bre. }\end{array}$ \\
\hline $\begin{array}{l}\text { 4. Es re fe ren cial: le da nom bres a per so nas, } \\
\text { ob je tos, co sas, lu ga res, et cé te ra, y cada uno } \\
\text { de ellos re pre sen ta una fun ción y ac túa } \\
\text { como mo tor po ten cial de he chos y ac cio nes. }\end{array}$ & $\begin{array}{l}\text { 4. Es vago des de el pun to de vis ta re fe- } \\
\text { ren cial en cuan to que no de sig na in di vi- } \\
\text { duos, sólo ca te go rías }\end{array}$ \\
\hline
\end{tabular}

$\mathrm{Al}$ analizar las características de los documentos no debemos limitarnos a su estruc turay forma solamente, nireferirnosa ellos como si fueran un fenómenoaislado ya que son producto de las sociedades que las generan. El cuadro anterior muestra queestasmismascaracterís ticas analizadasycomparadassonlasmismascaracterísticasdelaproduccióndocumentalactual.

\section{EL DOCUMENTO A TRA VÉSDE LAHIS TORIA}

Porsigloslosmaterialesutilizadosporelhombre(piedra,arcilla, maderapapel,etcétera) paradejarconstanciaalas fu tu ras gene raciones sobresusex periencias, activida des, pen sa mien tos o des cu bri mien tos porme dio delas pala bras, sím bolos oimá genes, no habían presentado tantos cam bios en tan poco tiem po como los que han surgidoenlasúltimasdosdécadas.

3 Raffaele Simone Idem. 146. 
Estos ma te ria les han va ria do su forma de acuer do con las téc ni cas y tec no logías utiliza das porlasso cie da des en dis tin tas etapas delahis to ria, y son el re fle jo del de sarrollo cultural de la humanidad en don de el pa pel es sin duda el me jor so por te (aun hoy en día) inven tadoparaes cribir, conservar, transportaryma ni pularlasin quietur desintelectualesdelhombre.

Sinembargo, actualmenteseen cuentran todavía ende sarrollolastecnologías más revolucionarias desde la invención de la escritura y la imprenta, y han cambiado en poco tiem polas formas y con te ni dos de lo que seha deno mi na do ge né rica men telibro,y des pués documento. Elimpac todees tas trans formaciones en elámbitodocur men tal se re fle ja en las diver sas formas de ela bo rar, divulgar, acce dery utilizarla información, las cuales han multiplicado sus representaciones, pero sobre todo, impactado las formas de apropia ción que de ellos ha cenlas dife rentes co mu nidades socialesyculturales.

El libro en so porte de pa pel fue el re presen tan te por ex celen cia delos do cu mentos, aun cuan do surgie rony tu vie ronsu apo geo en dis tintas épocas la divul ga ción de es tam pas, carte lesy, en los úl ti mos si glos, las re vis tas. Pero con la apa ri ción de la fotogra fíay la mi crogra fía ha cia fina les del sigloXIX, se ini cia una nue va eta pa en la representacióninformativa, puessegenera ronsoportesmagnéticos, ópticosyelectrónicos que permitieron, a me dia dos del siglo XX, la proli fe ra ción de al me nos me dio centenardediferentesmodelos dedocumentos, denaturaleza, formaycapacidades distintas. ${ }^{4}$

Acontecimien toscomo el térmi no dela segun dague rra mun dialylaaplica ciónde las'Tecnologías de la in for ma ción yla Co mu nica ción(TICs) en las ac tivida des in formativas, potencia ronlaproducción documentalygeneraron nuevasnecesida desde organización, recu pe racióny difusión de ellas. Loscambios más significa tivosserefie ren a su es truc turay so por te, yvan delo tex tual ala prima cía delaimagen, delo m aterialalointangible.

Comúnmente, undocumentosedefine comoun "Soportenaturaloartificialenel cualsehan re gis tra do unos da tos es critos, simbóli cos o sono ros," 5 o tam bién como "Unvehículode da tos rea les o in ten cio na dos, ex pre sa dos por me dio de sig nos convencionales, recuperables a través del tiempo y del espacio." En definiciones especializadas,JoséMartínezdeSouzalode fine como: "Expre sión delpensamien to (biogra fía, rela to, tex to) pormediode signosgrá ficos (le tras, dibujos, pin tu ra, etc.) s obre un so por te (piedra, perga mi no, pa pel, lienzo, cin ta, etc.)", ya su vez, Mijailov lo describecomoun "Objeto materialquere gistreo fijeunconocimiento."

PaulOtletiden ti ficay cla si ficalos principales elemen tos cons titu tivos deldocur mentodelasiguienteforma:

4 SagredoFernán dez,Félix y Ma. Blan ca Es pino sa Temiño. "Dellibro allibro elec tró nicodigital". En Cuadernos de documentación. Re vis ta en línea.

5 EnciclopediaSalvat 
1. Elementos materiales: sustancia, materia (soporte, superficie); forma material (figura), y dimensiones (formato).

2. Elementos gráficos (signos): texto; estructura fonética (alfabética); notaciones convencionales; ilustraciones; imágenes (reproducciones abstractas); dibujos (imágenes a mano); fotografías (imagen mecánica); esquema (diafragma, reproducciones abstractas) hechas a mano y resultado de una grabación mecánica; decoración del libro: figurines, viñetas, follajes.

3. Elementos linguiísticos: lengua del libro.

4. Elementosintelectuales: formasintelectualesdellibro(exposición, didáctica, retórica, géneros literarios, formas bibliotecológicas).

Existe también la corriente que amplía la concepción de documento a cualquier objetoquepuedaproporcionarin formación, comopuedenserlosobjetosnaturales, modelos, artefactos, realia, etcétera. Bajoesta mismalínea conceptualseencuentra la siguiente definición generada en la documentación francesa en los años 50, la cual consideraaldocumen to como "Todain dica ción con cre tao simbólica,preservaday registradaparareconstruiroproveerunfenómenofísicoointelectual”. ${ }^{6}$

\section{DOCUMENTOS DIGITALES}

La apli ca ción de las'TICsenlaproducción do cumen tal gene ródocumentosconca racterísticas acordesconelcontex tosocial,económico,culturalycientíficoenel que se crea ron. A pesardequeenun principio sólo se tras pa sa ronlos principales ras gos delos documen tosimpresos alos ambien tes electrónicos, muypron tosecompren dióquese es ta ba fren te aun fe nó me no nue vo que cada día po ten ciaba las ca paci da des y bonda desdeéstosdocumentosllamadosenunprincipioelectrónicosydespuésdigitales.

La utilización de medios y procedimientos informáticos, especialmente la computadora,parala elaboración, al macenamien toy di fusióndocumentalderivóenlos lla madosdocumentoselectrónicos, cuyosantecedentesseremontan propiamentea fi na les de la dé ca da delos 60 y prin cipios de los 70 , del si glo pa sa do, ya que an te riormen te el empleo dela com puta dora en un prin cipio seres trin gió al al ma cena mien to de datos estadísticos y programas matemáticos, además de que las computadoras sólo es ta ban dis po nibles en los gran des cen tros dein ves tiga cióno em pre sas. Con la difusióndelascomputadoraspersonales diversossectoressociales ampliaronsuuso yaplicación.

Las ven tajas brin da das pores tos me dios elec tró nicos como lagran ca pa cidad de al mace namiento, re cuperacióny transportacióndedatos, son aprovechadas paralaedi ciónmasivadepublica ciones, ya queademás delomencionadoanteriormenteéstas resultan mucho más económicas para los procesos editoriales además de permitir la combinacióndetextos, imágenes, videoyaudio,esdecir,deproductos multimedia.

6 Brief, ci ta do por Mi chael K. Buck land en "In for ma tion as thing”, p.355. 
En las biblio te cas los avan cesin for má ti cos se emplearoninicial menteparalagra bación de información bibliográfica, y subsecuentemente aparecieron las primeras basesdedatos,índicesycatálogosautoma tiza dos quefacilita ronlaorganización internadelas biblio te cas, y pos te riormen te surgie ronlos OPACs (OnLine Public Access Catalog) quepermitieronla realización deconsultasenlínea.

A pesardelas grandes di fe rencias que presen tanes tos do cumen tos elec trónicos existen similitudes importantes con sus antecesores de papel, como es el hecho de queen su mayo ríase trata de documentos termina dosy que sealmacenanen soportes físicos, yasea en los dis cos du ros de las computa doras, oenservidores, cin tas magnéticas, disquetes, CD-ROM o DVD, porlo que su tra ta mien to en elámbi to biblio te carioessimilaraldelosimpresos.

Con el de sa rro llo delas re des de co mu ni ca ción re pre sen ta das por la red de In ternetyla World Wide Web (Web), los proce sos do cu men ta les se po ten cian al permi tir la trans portación de documen tosporme dio dere desy sis te mas de comunicaciónaccesiblesen todo elmun do, pero ade más esto propicialagene ra ción de nuevas formas documentales enlascualeselsopor teyanoesfísicoyendondelasprincipales formas deproduccióny difusiónsedanatravésdelaInternet.

Conla In ternetem pie zan a coexis tirdocu men tos elec tróni cos re gis tra dos en soportes mate ria les (fue ra delínea) y docu men tos elec trónicos que no tie nen un soporte fí si co y que sólo exis ten en la red (y en línea, como son el co rreo elec tró nico, las pá ginasweb, elchat,etcétera)aloscualesseleshalla madocasisiempredigitales.

Auncuan dolos térmi nos elec tró ni co y di gitalseutilizanin dis tin tamentepara referirse a todo tipo de documentoscreados a partirdeprocedimientosinformáticos, existen definiciones creadas específicamente para describir los documentos digitales, comolasiguiente, quelos de fine como "[...]lase cuen cia deimá ge nes o ca racte res en forma deimpulsos elec trónicos, puntos magnéticosomarcas reflectivas." ${ }^{7} \mathrm{Lin}$ da Schambler, asu vez, lode fine comouna:"Unidad flexibleydinámica, con sistentede contenido no lineal, represen tadocomo conjun todeítems dein forma ción,enlaza dos, al ma cena dos en uno o más me dios físi cosoen Red, crea dos yutilizados poruno omasindividuoseneldesarrollodealgúnprocesooproyecto". ${ }^{8}$

Una definición interesante es la brindada por la legislación de depósito legal de South Africa, la que, aten dien doa laproblemática documentalenambientes digita les, de finealdocumen tocomo "[...]unobjetoqueintentaal macenarocomunicarinformaciónen formato tex tual, gráfico, visual, au ditivo, ocualquierotroformatolegiblea través de cual quierme dio. Unmedio significauna forma dere gistrarotrans fe rir in formacióncomoconsecuenciadeleer, escucharover".?

7 Noel Angulo. “Tran si ción:los docu men tos elec tró ni cos enlabiblio te ca”. EnTrans- in-formçcao. maio/agosto, 1997)

8 Lin da Scham ber. "What is the do cu ment? Rethin king the con cept in uneasy ti mes".

9 Lariviere, Jules En: Guidelines for Legal Deposit Legislation p.40 
Así,lasprincipalescaracterís ticasquealejaneldocumentodigitaldelimpresoson:

Físicas:

Soportes intangibles.

Uso:

Tienen una capacidad ilimitada de réplica, interactividad, así como la posibilidad de nave ga ción en múl tiples es pa cios ima gi na bles, y re de fínición delpa pel del lector, en donde "el monólogo del texto se convierte en diálogo". ${ }^{10}$ Hiperreferencia: posibilidad de ligar con otros documentos o información. Mutuabilidad y flexibilidad: posibilidad de modificar la información.

Facilidaddetransferenciaadiferentes formatos:(cinta, diskett,impresos, etcétera).

Facilidad instantánea de transportación.

\section{Contenido:}

Ordenamientosmúltiples, con op ciones parabus carlain forma ción de di ferente manera; supremacía de lo visual sobre lo textual.

Multimedios: Lain forma ción pue de sertex tual, sono ra, vi sual o una com bina ción de ellas.

Heterogeneidad: Un do cu men to pue de tra tar deva rios te mas con o sin re la ción entre sí.

Hipertexto: Es un modo no se cuen cial de la lec tu ra, una es cri tu ra que es tablece nexos conlos diferen tes no dos compren didosenun tex to. ${ }^{11}$ El hiper tex to aut men ta los es pa cios de liber tad dellec tor a tra vés dela aso cia ción no se cuen cial de elementos de conocimiento. Este nuevo tipo de escritura, permite que la es tructuradeldocumen to pueda ser: lineal (con un camino único y fijo); suceso único (don de no hay ca mi no que re co rrer); circular (ca mi no fijo y úni co, sin inicio y sin fin); indexada (menú de opciones que tienen respuesta y después regre san a un nue vo menú); lineal ramificada (se cuen cia principalque pue de es tar ramificada para luego volvera su es truc tu ra prin ci pal), y contributaria (el usuario puede añadir sucesos que después se convierten en una opción para nuevos usuarios). ${ }^{12}$ La tecnología utilizada en los hipertextos ha permitido la construcción de hiperdocumentos o hipermedia que facilita la reunión de todotipo dein for ma cióngráfica (imá ge nesmóviles, fijas, video y so nido) que puedesercodificadaen forma digitalparasualmacenamientoyrecuperación. Paraenlazardos tex tos di fe ren tes oiguales, elhipertex toutilizaloslenguajes de marcado para estructurar los documentos digitales independientemente del software utilizado. Actualmente los lenguajes de marcado más utilizados

10 Regis Debray. "The book as a symbolic object" En: The future on the book.

11 Tim Barnes- Lee. En Co rreo de la UNESCO.

12 Rami roLa fuen teLó pez. Biblioteca digitalyordendocumental. 
son en su mayoría derivaciones del Lenguaje Estándar Generalizado de Marcado (SGML), como se muestra en el esquema 1:13

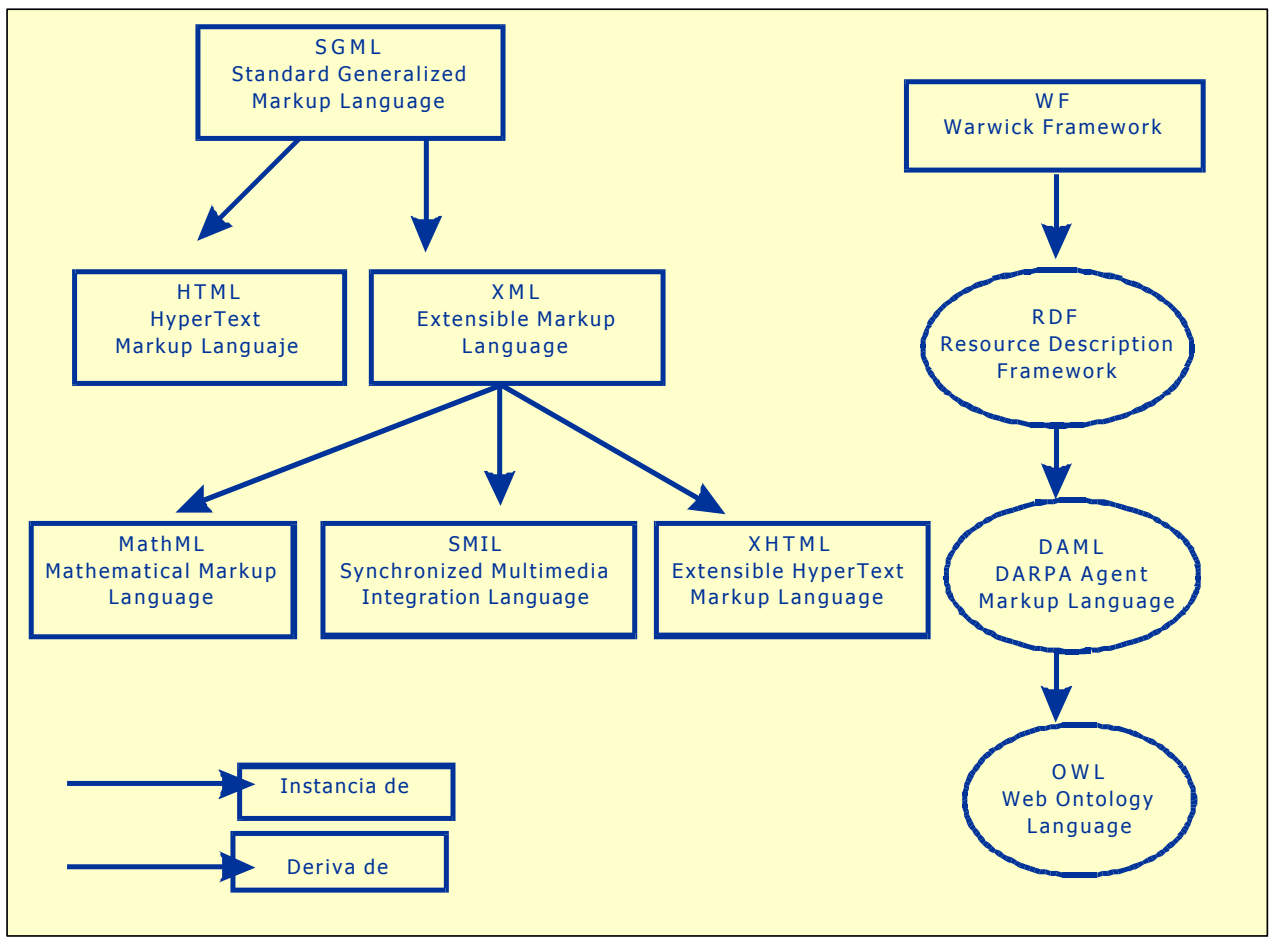

Esquema 1

Otra característica propia de los documentos digitales es que éstos se conforman porgru pos de objetos relaciona dos en tresí, que además deincluirda tos in for ma tivos proporcionandatosadicionalesparasucomprensión,administraciónydescripción

Las ventajas del documento digital sobre el impreso son múltiples ya que propicianla colabora ción en tre diver sos gru pos detrabajo, la comu nicaciónin te ractiva y dinámica, etcé te ra; sin em bargo, de bido a su re cien te apa rición exis ten du das sobre su permanen cia en el tiem po; es decir, la con serva ción efec tivadelain forma ción que resguarda,y tambiénsobrela fiabilidaddeloscontenidos.

Se debe considerar que el documento digital no es un producto terminado, lo que origina que no exis ta un solo tipo de do cu men tos digitales, ya que al es tar en cons tan te desarrollosus característicascambianyaumentandíacondía,comoseñalaLafuente:

13 Esquema basa do en Cris tian Vás quez. Loslenguajes de Meta datos. 
[...] eldocu men to en am bien tes digitales se adap tay mo di fica de acuerdo a las ne ce si da des oim po si cio nes de las nue vas tec no lo gías; lo que ha motivadoque sea vis to comounobje toúnico que represen ta nue vas realidades, usos y aplicaciones. ${ }^{14}$

Precisamenteestainestabilidad físicaytem poralesloquehageneradociertaspostu ras en trelos es tu dio sos del fe nó me no, que cues tio nan silo que se nos pre sen ta en pantallasiguesiendoundocumentooeltérminoyaquedórebasado.

\section{OBJETO DIGITAL}

Enlaactualidades frecuen te en con trarelusodel térmi no “obje to" paradesignar, no sólo las partes de un documento digital (en la mayoría de los casos figuras) sino también aquello que por su con ti nua trans forma ción impi de que se señalenca rac terís ticas propiasyde finidas so brelos objetosin forma tivosque aparecen enla pantalla de una computadora. En algunas ocasiones el término es empleado para referirse a las pá gi nas Web cuyo con te ni do prin ci pal no es tex to, sino ima gen, o para de sig nar algunapartedeesapágina.

Obje to digitalpue de de finirsecomo “[...]uni dad dein forma ciónde finidaporcódi gos que mues tran su ini cio y su fin", 15 o como “[...]cual quier uni dad de va lor o descrip ciónde con te ni do, da tos tex tos, mun doURML(Len gua je de mo dela ción de realidadvirtual), imagen, texturas, movimiento, conductaotransformación" ${ }^{16}$

Unobjetodigitalconsis tebá sicamenteenunasecuenciadebits que bajo una co rrectacodificaciónrepresentantodotipodeinformación,lacualpuedetomardosformas:

* Estructural: Interpreta los bits para organizarlos en tipos o grupos específicos de da tos y en oca sio nes da tam bién una des crip ción del hard ware y soft ware necesarios para acceder a ellos.

* Semántica: Le aporta significados adicionales a la información estructural que permiten identificar, por ejemplo, el idioma de un escrito. ${ }^{17}$

Al hablardeobjetos digitales es ne cesa rio men cio narlos me ta da tos, los protocolosylasetiquetas:

\section{Metadatos}

Sonelementos descrip tivos (atributos) deunobje to digital. Su propó si toesdocur men tary es truc turarlain for ma ción para co nocer y des cribirme dian te una me to dología, datos como: nombre, longitud o valores de validación de un elemento o un dato. A tra vés de es tos da tos, se pue den co no cer los cam bios rea li za dos en los ob jetos digitales, establecerrelacionesy,endeterminadoscasos, la autenticidadde ellos.

14 RamiroLa fuen teLópez. Biblioteca digitalyordendocumental.

15 La información en el inicio de la era electrónica: información, sociedadytecnología. p165

16 Alex Galloway. Qué son los estudios digitales?

17 Preservation metadata for Digital Objects: a review of the state of the art., OCLC/RLG p. 13 
Elnú me ro deelemen tos utilizados para des cribirlos objetos digita les va ría de acuerdocon los propó si tos para los cua les seutilicen, sin em bargo los más di fun di dos son los pro pues tos porel sis te madelDublínCore(Dublin CoreMe ta da ta forSim ple Resource Dis co very) que de fine un nú cleode 15 elemen tos. Comúnmentelos meta da tos son comparados con prácticas similares a la catalogación y la bibliografía, pero aplicados en ambientes electrónicos. Sin embargo actualmente los metadatos son utilizados en tres categorías:descriptiva(identifica recursos deinformación), administrativa (facilitalages tiónyelprocesa mientodecolecciones digitales),yestructural (facilitanlanavegaciónypresentación delos recursos).Esimportanteseñalarque el "objetodigital"y sus me ta da tossonas pec tos diferentes delmismoobjeto, auncuandose encuentreninmersosenél.

\section{Etiquetas}

Son los ele men tos que per mi ten laiden ti fi ca ción de los cam pos en don de está representadaestainformacióndigital.Supropósitoesfacilitarlarepresentación de ésta in for ma ción digital a tra vés de marcas o sím bo los que se in cor po ran a las par tes que constituyeneldocumento, conelfindeidentificarlocomoobjeto.

\section{Protocolos}

Sonun con jun to dereglas utiliza das para en viarmen sajesentre sis te masinformá ticos ${ }^{18}$ que re gu lan el flu joy di rigen el es pa cio en la Red, ade más de que co di fi can las relaciones y establecen vínculos. Su creación se sustenta en la idea de ser un medio para es truc tu rarla in for ma ción, in de pen dien te del tipo de soft ware que se utilice. El organismo que promueve la normalización de los protocolosy formatosutilizados es el World Wide Consortium(W3C), que además de pro porcio narin formación sobrelaWebpresentaejemplosqueayudanapromoverlasnormasrecomendadas.

\section{IMPACTO DEL DOCUMENTO-OBJETODIGITAL EN LA BIBLIOTECOLOGÍA}

La bibliotecología basa sus estudios en la información documental, y por ello la producción,lacon servación,la organización, elanálisis,la re cuperaciónyla difusión delos documen tos son ob je to de es tu dio dela dis ciplina.Poresta razónes necesario conocer elmarco contex tualen el que se desenvuelven es tos as pectos para sa tis facer lasnecesidadesactuales dein formaciónyan ticiparsealas futuras exigencias sociales. Algu nas delas repercu siones másim portan tes del do cumen to/obje to digitalenlas funciones y actividades bibliotecológicas se refieren a la producción, la conservación,lacatalogaciónyclasificación, larecuperaciónyelaccesointelectual.

18 Ernesto García Ca ma re ro y Luis Án gel García Mele ro. Labibliotecadigital, p. 57. 


\section{Producción}

No existe un control sobre los documentos que aparecen en la Red en cuanto a forma to ynúme ro.Lalibre apro pia ción delos docu mentos, ya sea en formacompletao suspartes, propiciala proliferaciónde trabajosduplica dosy estodificul tal a identificación de los autores ya que en su mayoría los documentos no son producto de una sola en tidad y se for man a par tir de las con tribu cio nes de mu chas per so nas, además de queuna gran can tidad dees tos do cu men tos-obje to no in clu yen la men ción de autoría.

Aunadoaloan terior, tambiénsepresen tan problemasparaestablecerlaveracidady autenticidaddelos documentos, auncuando P. Otletyaseñalabaque: "Eldocumento tieneen co mún conla pala brala po sibilidad depresentar fala cias, fal sas atribuciones a los autores erróneos, falsas fechas, falsas indicaciones de autor, de impresos, de edición". ${ }^{19}$ Sin embargo es tas posibilida des deerrory fal sas atribu ciones aumentan conla produccióndelos documentos digitales, porloque enla ac tualidadexistengrandes debates so brela protección delos derechos de au toryla de tección de do cumentos du plicadososobrelosque existeunaapropiaciónindebida.

Otro as pec to muyimportan te es quela mez cla de au to res enun mis modo cumentolos convier te asu vez en sus principales con sumido res, porlo que po de mos hablar de "pro sumidores de in formación"; estoes, produc to res y con sumidores al mis mo tiempo. 20

\section{Conservación}

La falta deunade finiciónade cua da so brelos documentos/objetos digitaleshaoca sionado grandes discusiones sobre si estas nuevas formasdocumentarias deben o no sercon sideradas en los programas de conserva ciónporlas diferentesins titu cionesdocumentalesasícomo porlaslegis la cionesdeDe pó sitoLegalen dis tin tos países.Enlas diferentesins tancias re cep to ras no exis te un consen so so bre si se tra ta de documentos (comoselosconcibetradicionalmente)ono,ysiés tosdebenserpreservados.

Lo anterior aunado a que la producción instantánea de documentos provoca tambiénsuinstantáneadesaparición,loque conllevaproble mas delocalización,almacenamiento y recuperación, que a su vez ocasionan lagunas informativas y la pérdidadeinformaciónvaliosa. Así,lavalo ra cióndocumentalen frentaproblemas so bre lo que debe ser con serva do, lo que es va lio so y lo que pue de sercon si de rado comoundocumento.

Otro pro ble ma dela con serva ción do cu men talen am bien tes digita les es que ala par del documento/objeto, se recomienda preservar también los programas informá ticosqueloscrearon, lain fraes truc tu ra necesa riaparaacce dera ellos, los me ta datos y la des crip ción de los cam bios efec tua dos a tra vés dela his to ria del do cu men to,

19 Paul Otlet. Eltratado de do cumen tación. Ellibrosobreellibro.

20 Término utilizado por Alejandro Pis chi telli. en su Foro de discusión y redacción colaborativa. 
como son los cam bios de for ma to en la trans fe ren cia o migra ción de la in for ma ción, yaqueestopuedeocasionarcambiosdesignificadoenlosdocumentos.

El tema se en cuen tra au sen te en la gran ma yo ría de las le gis la cio nes so bre la conservación legal, en tan to que otros países se ade cuan ala pro ble má tica y previe nen accio nes de pre serva ción, como es con si de rar obje tos de con ser va ción a to dos los registros informativosque se en cuen trenen formas electrónicas, digitalesocualquier otraformaqueenelfuturoaparezca. ${ }^{21}$

\section{Catalogación y clasificación}

Elcam bio, y en ocasio nes la fal ta de es truc tu ra, jerarquía y se cuen cia delos tex tos, dificulta elanálisis yladescripcióndelos documentos/objetos digitales, enlos que el tex to, en la ma yo ría de los ca sos, no es el ob je to prin ci palde des crip ción, lo que oca siona que los sistemas tradicionales de clasificación no necesariamente resulten los mejoresparaorganizarestetipodemateriales digitales.Porejemplo¿cómoclasificar imáge nes y tex tos en un mis mo do cu men to? ¿c uál es elva lor pri mor dial? ¿c uál es la formamásadecuadaparaclasificarimágenesenlared?

Ade más esta nue va cul tu ra deloes cri to ha pro picia do nue vas for mas de apro piacióndelos tex tos y dela lec tu ra, en don delos do cumen tos/obje tos digitales pue den sermás fácilmentemanipula dosporlos usua riosyadaptadosa necesidadescadavez más individuales; es de cir,es ta mos ante un fe nó me no no sólo re fe rido a la can tidad de documentos generados, sino que además éstos son diferentes, en muchos casos personalizadosy, alno exis tiruna tipologíaúnicade documentos, sus ca racterís ticas semultiplican,locualdificultasudescripciónyconsecuentemente, suorganización.

\section{Recuperación}

Se gúnIreneWormell, ${ }^{22}$ el ac ce so al co no ci mien to del hombre se pre sen ta en tres vertientesquesonsuaccesofísico, bibliográfico, eintelectual.

Acceso físico: Los documentos/objetosdigitalesnecesitande una combinaciónde fac to res para que se pue da dis po ner de ellos: in for ma ción para ac ce der a ellos (pueden ser manuales, instrucciones),permisos (copyright, canda dos), software, equipo físico,conocimientoscomputacionales, etcétera.

Accesobibliográfico:Las posibilidades de recupe rardocumentosatravés delosca tá logosbibliotecariosha aumentado, yaqueademásdepoderrecuperarlain formación documental a través de los encabezamientos de materia, palabras clave, códigos de clasificación, etcétera, ahora las posibilidades de recuperación aumentan en estos ambientes, porque sepue de ob tenerundocumen toen tex to com ple too sólo al guna

21 South Africa. Le galDeposit, cita do en Guidelines forlegal de po sitle gis la tion, $\mathrm{p} 40$.

22 Irene Wormell. Subject access redefined: how new technology changes the conception of subjectrepresentation. 
de sus partes, como son las grá fi cas, ta blas de con tenido, no tas y ci tas, bi blio gra fías, etcétera. ${ }^{23}$

Accesointelectual: Es elretomás difícilalque seen frentalaprofesiónbiblio tecóloga, pues debe buscar las me jo res y más ade cua das for mas para que los usua rios pue dan accedera la parteintelec tual delos contenidos. Los nuevos programas com putacionalespueden recuperarautomáticamenteeldocumen to completoopartedeél,pero laparteintelectualnecesariaparainterpretarlasnecesidadesdeinformacióncada vez más especificas de los usuarios sólo puede ser proporcionada por la parte humana, porloque el bibliote ca rio debe des tinargran parte de su tiem po, ade más del aprendiza je so brela utilización de és tos pro gra mas, ain ves tigarlasme jo res mane ras deproporcionaresteaccesointelectualalosdocumentos.

A la parque es tu diary analizarlas partes que com poneneldocumento/obje todigital(lo tex tualy lo digital,las tecnologíasenInternet,la nave ga cióndeobjetos digita lesylosmetadatos) sedebenestudiarloscambioscul turales, tecnológicos, económicos y sociales en los que todo esto se produce, ya que tales cambios determinan su formayutilización porparte delas dis tin tas comunida des. Unejemplodeesto sonlas característicasde las sociedades actuales; pues aun cuando la mayoría de ellas se encon tra ba den trodela lla mada cul tu rapro posicional, aho ra mu chasse muevenenes que mas no pro po si cio na les en los que por ejem plo un tér mi no vago pue de o no englobartodoloquequeremossignificarcomoundocumento.

Loscambiosenlarepresentación del conocimien toobliganareplantearelconcepto que so bre el do cu men to se tie ne enla dis ciplinabiblio te co ló gica. Lluís Codina afirma que "[...] existen dos momen tos paraavanzarenlas cien cias. Unoconsis te en relacionar cosasaparentementedesconectadas y es, por tan to, unmovimientodeampliación[...] perotambiénseavanza encien cia realizan do reduc ciones, es de cires tableciendo relaciones conotras cien cias yen riquecersemutuamente, odelimitandoconclaridad suslímites." 24 Aunque se debe tener mucho cuidado al respecto, ya que como menciona EdgarMo rin: "Con res pec to alas co sas más im por tan tes, los concep tos no se de finen ja más porsus fron te ras, sino a partir desunú cleo." ${ }^{25}$ La im portan cia delo an te riorpuede resumirse en lo que menciona P. Otlet al respecto: "Definir una palabra desde el pun to de vistadeunaciencia es de limitarexactamentey conpreci siónelsentidodesde elpuntode vis ta delacien ciaconsiderada[...]Unadefinicióndebeserunplan teamiento pre cisodelas cualida desne ce sa rias y su fi cientes para crearunaclase (ca tego ría)con el fin de in di carlas co sas que per te ne cen o no a esta cla se." ${ }^{26}$ Es im portan te recordarque los con cep tos en las cien cias no sólo na cen, sino que cre cen y mue ren, lo que les permitealosconceptosrenaceryadaptarseanuevasnecesidadesdelasciencias.

23 Irene Wormell. Idem, p. 432.

24 Lluís Codina. "Ges tióny tra ta mien todelain formación documen tal:una propues tasdbre sus lí mites y propiedades."

25 Edgar Morin Introducción al pensamiento complejo. p.105.

26 P. Otlet Op. Cit. p. 12. 


\section{A MANERA DE CONCLUSIÓN}

1.- Las dis cu sio nes so bre lo que debe ser con side ra do como do cu men to y porlo tanto, su de fini ción, han sido cons tan tes du ran te elúl timo siglo, y se han cen trado en los siguientes aspectos:

* Propósito de elaboración: considerar como documentos sólo a los objetos rea li za dos con la finali dad de in for mar, serpu blica doso que in clu yan in formación cognitiva, lo que delimita el campo documental; sin embargo, hay que considerar que muchos documentos resguardados en bibliotecas y archivos no fue ron rea liza dos con estain ten ción, como porejem plo los do cur mentos elaborados con finalidades decorativas.

* Uso como do cu men to: el hom bre no sólo se in for ma con obje tos in ten ciona dos para tal efec to sino con todo tipo de ob je tos que le pro por cio ne in formación, lo que abre el espectro a infinidad de objetos materiales, y ahora inmateriales, ya que todo objeto implícita o explícitamente proporciona mensajes que pueden ser interpretados por los individuos.

2.- En este nue vo mun do tex tual, vi sual y do cu men tal, ¿qué tipo de do cu men tos informa tivos sonobje to de es tu dio delabiblio te cologíay cuáles no? ¿conquéotras disciplinas habrá que relacionarse y con cuáles habrá que marcar límites? Es el momentoadecuadoparaconsiderarotros paradigmas paraes tudiarelfenómeno documental, como puede ser el paradigma de la complejidad propuesto por EdgarMo rin quien co nec ta la teo ría con la me to do lo gía, la epis te mo lo gía y la onto logía para pen sar el ob je to de es tu dio delas cien cias no como algo aca ba do sino en continua transformación y relación con su exterior, lo que nos obliga a plantearlaposibilidaddetrabajarconlatrans diciplinariedadylamultidisciplinariedad comoas pec tos fun damentales que permiten elcre cimien to deladis ciplina como tal en el contexto científico.

El documentoelemental correspondealpen samientodiscursivo. Sirvedeapoyoa este pensamiento permitiéndole un desarrollo explícito cada vez más extendido y abundan te. Eldo cumen to de gra do superiorquese en treve co rrespon de ría alpensamien to in tuitivo. Despojaríaaldocumentoelementalde suspropiedadesfundot mentales físicasy psi co lógicaspara subli marloy re ducir apoca cosa su subs tra to como la serie encadenada de signos [...] Con una ascensión extrema llegaremos a concebir una documentación sin documentos. 


\section{BIBLIOGRAFÍA CONSULTADA}

Angulo, Noel. "Transición: los documentos electrónicos en la biblioteca”. En Trans-in-formacao. (Publicao quadrimestral, v9, no.2, maio/agosto, 1997)

Berenguer, Xavier. Laestructuradellenguajevisualdinámico. Curso In te ractividad y ficción.

Buckland, Michael K. "Information as Thing". En Journal of the American Society for Information Science. 42 (5): 351 - 360, 1991.

Codina,Lluís. "Ges tión y tra ta mien to delain forma ción do cu men tal:una propues tasobresus límites y propiedades". En Elprofe sionaldela infor mación, vol. 8, no. 5, mayo de 1999.

Cruz Paz, An drés. "En tor no a los con cep tos do cu men to, fuen te y re curso en la cien cia de la in for ma ción”. En Ciencias dela In formación (vol. 23, no.4, dic,1992).

Galloway, Alex. Qué son los estudios digitales? http://aleph-arts.org/pens/digitalstud.html consultado el 29/05/2003

García Camero, Ernesto y Luis ángel García Melero. La biblioteca Digital. Madrid: Arco/Libros, 2001.

Correo de la UNESCO. Francia: UNESCO, 2000 (sep.)

Debray, Re gis. "The book as a sym bo lic ob ject" En The fu tu re on the book. Geoffrey Nunberg, editor. Berkeley: University of California, 1996 p 139-151.

Internet, Metada tosy Acceso a la In formación en Bibliote casy Re desen la Era Elec trónica.Comp. Filiber to Felipe MartínezArella noy Lina Es calona Ríos. México: CUIB/INFOCONSULTORES; 2000.

LafuenteLópez, Ramiro. Bibliotecadigitalyordendocumental.México: UNAM /CUIB, 1999.

Lariviere, Jules. Guidelines for legal deposit legislation. París: UNESCO, 2000 http//www.unesco.org/webworld/publications/legaldeposit.rtf consultado 23/05/03

Lévy, Pierre. ¿Qué es lo virtual?. México: Paidós, 2000

Lainformaciónen elinicio delaeraelectrónica:información, sociedadytecnología. México: CUIB/UNAM, 1998, p.165.

Mo rin, Edgar.Introducciónalpensamientocomplejo.Barcelona:Gedisa;1990.

Otlet, Paul. Eltrata do de documentación. Ellibro so breellibro. Tr. Ma ría Do lores Ayuso Garcían. Murcia: Universidad de Murcia, 1995 
Pischitelli,Alejandro. Foro de discusiónyredaccióncolaborativa. Unaexperiencia transcátedras. Clase 1: Historia de la inteligencia

http://www.ilhn.com/datosuba/archives/000067.html

Consultado el 28/05/2002

Preservation Metadata for Digital Objects: A review of the state of the art. OCLC/RLG Working Group on Preservation Metadata. (January 31, 2001)

http.//www.oclc.org/research/pmwg/presmeta_wp.pdf Consultado el 22/07/2003

Rendón Rojas, Miguel Ángel. Bases teóricas y filosóficas de las Bibliotecología México: CUIB, 1998.

SagredoFernández,Félix y Ma. BlancaEs pino sa Temiño. "Dellibroallibroelectrónicodigital”. En Cuadernosdedocumentación. Revistaenlínea.

Schamber, Linda. "What is the document? Rethinking the concept in uneasy ti mes". In Journalof the American Society forinformation science. (v47, no.9, p669-671, 1996)

Smith, Terence R. A gene ral fra mework for the me ta-in for ma tion and ca talogs in digital libraries.

http://www.computer.org/conferences/meta96/smith/ieee.html consultado 24/08/2000

Simone, Raffaele. Latercerafase:formas desaberqueestamosperdiendo.México: Taurus, 2001.

Vásquez, Cristian. Los lenguajes de metadatos. http://www.dcc.uchile.cl/ cvasquez/meta/lenguajes.html Consultado el 24/07/2003

Wormell, Irene. "Subject Access Redefined: How New Technology Changes the Conception of Subject Representation". In Knowledge Organization and Quality Managment. Ed. Hanne Albrechtsen 431-439. Frankfurt: Indeks Verlang; 1994.

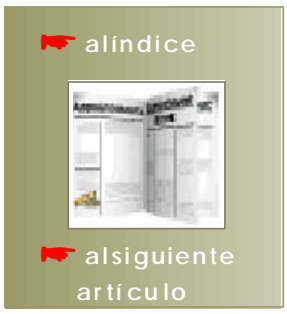

SALIF
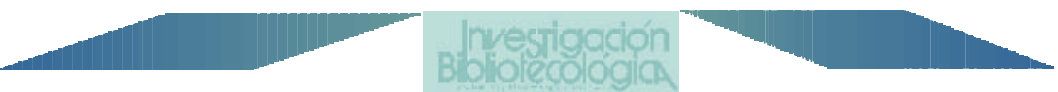